\title{
Comment on "Abuse and Misuse of Pregabalin and Gabapentin: A Systematic Review Update"
}

\author{
Udo Bonnet $^{1,2}$ (D) Heath McAnally ${ }^{3,4} \cdot$ Norbert Scherbaum $^{2}$
}

Accepted: 28 February 2021 / Published online: 18 March 2021

(c) The Author(s) 2021

\section{Dear Editors,}

We read with great interest the informative and well-conducted systematic review update by Evoy et al. [1] about the risks of gabapentinoid (GP) use (and misuse). The authors concluded that evidence suggests that GP-misuse/abuse is growing and comprises a significant individual and public health threat [1]. However, as the authors stated in their Limitations section, the studies included offer limited generalizability [1] due to small sample sizes, mostly retrospective designs and homogenous cohorts of opioid- and other substance-dependent subjects [1]. Clinical studies focusing on individuals without past and/or present substance use disorders are clearly lacking.

From a standpoint of scale, not only are reported outcomes (frequently surrogate in nature as admitted by the authors [1]) relatively rare, we are aware of only a miniscule number of patients worldwide seeking treatment for GP misuse/addiction. The emergence of a substantial sample seeking detoxification and other addiction medicine services should be a conditio sine qua non for a widely used/misused, allegedly strongly addictive, and thereby potentially

This is letter relates to the original article available at https://doi. org/10.1007/s40265-020-01432-7.

Udo Bonnet

udo.bonnet@uni-due.de

1 Department of Psychiatry, Psychotherapy and Psychosomatic Medicine, Evangelisches Krankenhaus Castrop-Rauxel, Academic Teaching Hospital of the University of Duisburg/ Essen, Castrop-Rauxel, Germany

2 Department of Psychiatry and Psychotherapy, Faculty of Medicine, LVR-Hospital Essen, University of Duisburg-Essen, Essen, Germany

3 Northern Anesthesia and Pain Medicine, LLC, Eagle River, AK, USA

4 Department of Anesthesiology and Pain Medicine, University of Washington School of Medicine, Seattle, WA, USA socially harming substance; and yet we have not yet witnessed this phenomenon despite years of opportunity for its development.

From the perspective of evidence-based medicine (EBM), level I experimental studies use randomized, prospective experimental designs to confirm causal relationships [2] not unequivocally derivable from non-experimental observational studies [3]. Although regulatory approval/disapproval does not always require randomized trials at every level of decision making, whenever randomization is not possible, the effect of various predictors and confounders must be taken into account in the planning of the study and in data analysis [3-6]. We are not aware of studies that have done so sufficiently to support presumptions of a causal connection between GP-use/misuse and related harms including psychological dependence and death. For example, a PubMed ${ }^{\circledR}$ database search using the key words "mediation analysis" [5] and "gabapentin" or "pregabalin" linked to "harm" or "addiction" or "abuse" or "dependence" or "use disorder" or "death" or "respiratory depression" did not reveal any human studies. Among 46 new observational studies, there were only very few (either small or less specific or too homogeneous (opioid users)) prospective investigations involving the topic of GP addiction and deaths (c.f. Table 1 in [1]). Well-powered and controlled [3-6] prospective trials comparing the occurrence of psychological dependence and deaths in an opioid-dependent sample versus a general population-based sample are needed to identify possible key effect modifiers.

We would like to provide some further information aimed at balancing the assessment of GPs' risk:benefit profile. As mentioned above, there is a glaring paucity of clinical studies about the addictive power/harms potential of GP-apart from the studies utilizing limited cohorts of people with other substance-use disorders [1]. Into this dearth we can add a clinical cross-over study showing that GP-dependence (assessed by face-to-face DSM-IV-based SKID-I interview) was quite rare in the elderly population of a German 
metropolitan general hospital: among 400 randomized patients, of whom 28 (7\%) demonstrated dependence on other non-opioid analgesics (NOA, primarily non-steroidal anti-inflammatory drugs (NSAIDs) and metamizole), two patients $(0.5 \%)$ reported de novo GP dependence (mild to moderate) along with concurrent NOA dependence [7]. Only one patient $(0.25 \%)$ demonstrated isolated GP dependence [7]. In line with the current literature [1], this person was (previously) opioid dependent; his current gabapentin dependence was rated as mild according to SKID-I, the German successor to SCID-I [7].

In addition, we have recently published an expert evaluation/harms ranking for various (and primarily psychotropic) drugs including an index assessment of GP; the GP ranked at the low end of physical, psychological, and social harms to both users and others [8, Supplementary Material]. Figure 1 contrasts drug harms with benefits [9], first of all reflecting the view of German addiction medicine experts, which might not be generalizable to other countries experiencing opioid misuse/abuse epidemics (so far, Germany is not). Nevertheless, we too are aware of a good portion of GP co-using patients admitted to our detoxification-units from illicit drugs, mostly opioids [10].

GP certainly may confer euphoria and relaxation, especially at hyper-therapeutic doses $[1,11]$, and yet along those very lines, unlike other rewarding substances, possess a wide therapeutic window. This property renders them thus considerably safer among persons with other substance addictions. And from a comparative-risk (and harm-reduction) standpoint it may be worth considering the possibility that GPs (which are less dangerous than other drugs such as benzodiazepines, barbiturates, antihistamines/promethazine [12], NSAIDs, acetaminophen [13], and even alcohol) might exert a protective effect (via substitution for these higher-risk coabused substances) in the opioid-misusing/abusing populace ("anti-adverse selection" hypothesis [11])—although this has not been investigated. Such an investigation supporting either synergism or antagonism-retrospective by necessity-would also be useful given the increasing recognition that most drug-overdose deaths involving opioids also involve other drugs $[12,14]$.

Also, among the substance-abusing populace, GPs demonstrate positive benefit in terms of amelioration of withdrawal symptoms from alcohol (EBM-levels II-Ia [15-19]) or opioid dependence (EBM-levels II-Ib) $[19,20])$ and per one randomized trial, also cannabis dependence (EBMlevel Ib [21]). This is important from a clinical standpoint in that withdrawal is one of the main triggers for relapse to substance dependence, and in that context, GP may serve as a significant therapeutic modality in addiction medicine

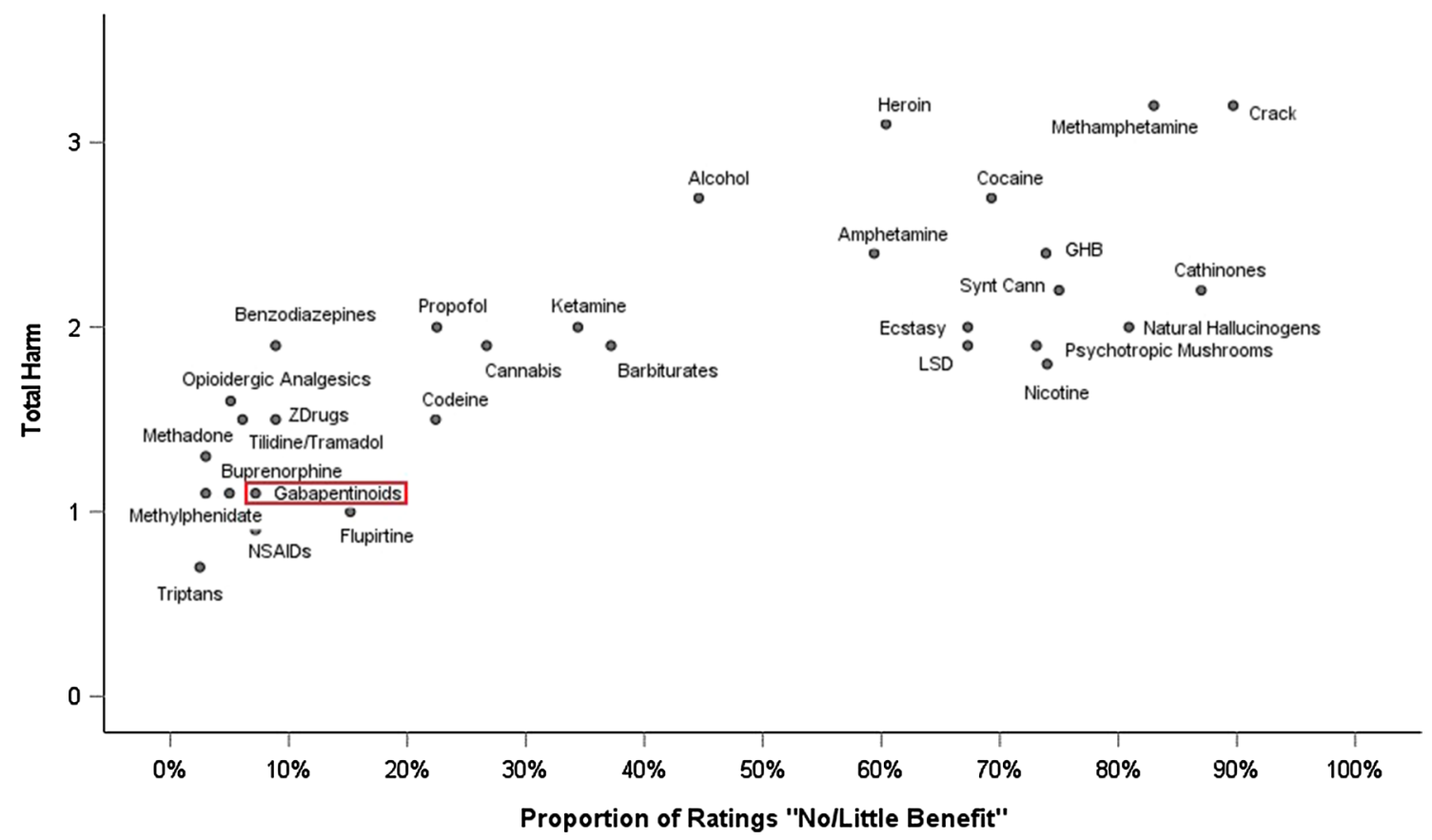

Fig. 1 Scatter diagram showing the assessment of the average overall harm of a substance in relation to its average benefit assessment (category: "no/little benefit"). Two groups are already visually demarcated (lower left square: prescription drugs; upper right square: traditional drugs of abuse except of cannabis and ketamine). Assessments were performed by 101 German physicians both specialized in addic- tion medicine and working for a median of 15 years in the tertiary care of patients with substance-use disorders $[9,10]$. Note that this assessment is not representative for countries dealing with an opioid epidemic (where the potential synergy/opioid-sparing features of gabapentanoids (GPs) or other CNS depressants might be more salient) 
[19]. Conversely, amelioration of withdrawal can serve as a hedonic reward in its own right, potentially leading to psychological dependence.

GP may also increase risk for adverse outcomes among substance-abusing persons by synergistic CNS (and perhaps respiratory) depression. The latter has not been proven mechanistically nor clinically [22], but does pose a conundrum when considering their use in this high-risk population. Furthermore (not unlike naltrexone treatment of opioid-use disorder), reversal of tolerance to sedative and respiratory depressant effects by the abused drug is a substantial concern [23].

The prescription of GP thus requires very careful and individual benefit:risk stratification [22], along with effectiveness and harm monitoring, and vigilant tapering/discontinuation when risks begin to outweigh benefits. From our clinician point of view, GPs are a highly useful and rather safe pharmacological armamentarium not only for neuropathic pain and some neuropsychiatric disorders, but also in the world of addiction medicine. More evidence from sufficiently controlled prospective observational [3-6] or, if possible, randomized clinical studies about their addictive and harms potential are required before further unfounded castigation (with resultant supply diminishment threat and potential attendant harms).

\section{Declarations}

Funding Open Access funding enabled and organized by Projekt DEAL.

Conflict of interest The authors declare that they have no conflict of interest related to this letter, except that they themselves had carried out two reviews about the highly debated topic of pregabalin's and gabapentin's harms and addiction [11, 22]. Furthermore, Norbert Scherbaum received honoraria for several activities (advisory boards, lectures, manuscripts) from AbbVie, Camurus, Hexal, Janssen-Cilag, MSD, Medice, Mundipharma, Reckitt-Benckiser/Indivior, and SanofiAventis. During the last 3 years he participated in clinical trials financed by the pharmaceutical industry.

Open Access This article is licensed under a Creative Commons Attribution-NonCommercial 4.0 International License, which permits any non-commercial use, sharing, adaptation, distribution and reproduction in any medium or format, as long as you give appropriate credit to the original author(s) and the source, provide a link to the Creative Commons licence, and indicate if changes were made. The images or other third party material in this article are included in the article's Creative Commons licence, unless indicated otherwise in a credit line to the material. If material is not included in the article's Creative Commons licence and your intended use is not permitted by statutory regulation or exceeds the permitted use, you will need to obtain permission directly from the copyright holder. To view a copy of this licence, visit http://creativecommons.org/licenses/by-nc/4.0/.

\section{References}

1. Evoy KE, Sadrameli S, Contreras J, Covvey JR, Peckham AM, Morrison MD. Abuse and misuse of pregabalin and gabapentin: a systematic review update. Drugs. 2020. https://doi.org/10.1007/ s40265-020-01432-7 ((Online ahead of print)).

2. Oxford Centre for evidence-based medicine: levels of evidence. 2009. https://www.cebm.ox.ac.uk/resources/levels-of-evidence/ oxford-centre-for-evidence-based-medicine-levels-of-evidencemarch-2009. Accessed 1 Jan 2021.

3. Thiese MS. Observational and interventional study design types; an overview. Biochem Med (Zagreb). 2014;24(2):199-210. https://doi.org/10.11613/BM.2014.022.

4. Baron RM, Kenny DA. The moderator-mediator variable distinction in social psychological research: conceptual, strategic, and statistical considerations. J Pers Soc Psychol. 1986;51(6):117382. https://doi.org/10.1037//0022-3514.51.6.1173.

5. Hayes AF. Mediation, moderation, and conditional process analysis. 2nd ed. New York: Guilford Press; 2018.

6. Gianicolo EAL, Eichler M, Muensterer O, Strauch K, Blettner M. Methods for evaluating causality in observational studies. Dtsch Arztebl Int. 2020;116(7):101-7. https://doi.org/10.3238/arztebl. 2020.0101.

7. Bonnet U, Strasser JC, Scherbaum N. Screening for physical and behavioral dependence on non-opioid analgesics in a German elderly hospital population. Addict Behav. 2019;90:265-71.

8. Bonnet U, Specka M, Soyka M, Alberti T, Bender S, Grigoleit T, Hermle L, Hilger J, Hillemacher T, Kuhlmann T, Kuhn J, Luckhaus C, Lüdecke C, Reimer J, Schneider U, Schroeder W, Stuppe M, Wiesbeck GA, Wodarz N, McAnally H, Scherbaum N. Ranking the harm of psychoactive drugs including prescription analgesics to users and others - a perspective of German addiction medicine experts. Front Psychiatry. 2020;11:592199. https://doi. org/10.3389/fpsyt.2020.592199.

9. Bonnet U, Specka M, Soyka M, Alberti T, Bender S, Hilger J, Hillemacher T, Kuhlmann T, Kuhn J, Lüdecke C, Reimer J, Schneider U, Schroeder W, Stuppe M, Wiesbeck G, Wodarz N, Scherbaum N. Weighing the benefits and harms of psychotropic and analgesic substances-a perspective of German addiction medicine experts. Fortschr Neurol Psychiatr. Fortschr Neurol Psychiatr. 2021. https://doi.org/10.1055/a-1363-0223.

10. Specka M, Kuhlmann T, Sawazki J, Bonnet U, Steinert R, Cybulska-Rycicki M, Eich H, Zeiske B, Niedersteberg A, Schaaf L, Scherbaum N. Prevalence of novel psychoactive substance (NPS) use in patients admitted to drug detoxification treatment. Front Psychiatry. 2020;11:569. https://doi.org/10.3389/fpsyt. 2020. 00569.

11. Bonnet U, Scherbaum N. How addictive are gabapentin and pregabalin? A systematic review. Eur Neuropsychopharmacol. 2017;27(12):1185-215. https://doi.org/10.1016/j.euroneuro.2017. 08.430 .

12. Chiappini S, Schifano F, Corkery JM, Guirguis A. Beyond the "purple drank": study of promethazine abuse according to the European Medicines Agency adverse drug reaction reports. J Psychopharmacol. 2021. https://doi.org/10.1177/0269881120959615 ((Epub ahead of print)).

13. Serdenes R, Graham J 3rd. Evaluating the psychiatric benefits of formulating acetaminophen with $\mathrm{N}$-acetylcysteine. Front Psychiatry. 2020;11:564268. https://doi.org/10.3389/fpsyt.2020.564268.

14. Peppin JF, Raffa RB, Schatman ME. The polysubstance overdosedeath crisis. J Pain Res. 2020;13:3405-8. https://doi.org/10.2147/ JPR.S295715.

15. Ahmed S, Stanciu CN, Kotapati PV, Ahmed R, Bhivandkar S, Khan AM, Afridi A, Qureshi M, Esang M. Effectiveness of gabapentin in reducing cravings and withdrawal in alcohol use 
disorder: a meta-analytic review. Prim Care Compan CNS Disord. 2019;21(4):19r02465. https://doi.org/10.4088/PCC.19r02465.

16. Quintero Garzola GC. The use of gabapentin for the treatment of alcohol and tobacco use disorders: a review. Open Access J Clin Trials. 2020;12:43-60. https://doi.org/10.2147/OAJCT.S257556.

17. Ghosh A, Mahintamani T, Choudhury S, Sharma N, Das S. The effectiveness of non-benzodiazepine, non-barbiturate medications for alcohol withdrawal syndrome: a rapid systematic review. Alcohol Alcohol. 2020. https://doi.org/10.1093/alcalc/agaa125 (Epub ahead of print).

18. Cheng YC, Huang YC, Huang WL. Gabapentinoids for treatment of alcohol use disorder: a systematic review and meta-analysis. Hum Psychopharmacol. 2020;35(6):1-11. https://doi.org/10.1002/ hup. 2751.

19. Ahmed S, Bachu R, Kotapati P, Adnan M, Ahmed R, Farooq U, Saeed H, Khan AM, Zubair A, Qamar I, Begum G. Use of gabapentin in the treatment of substance use and psychiatric disorders: a systematic review. Front Psychiatry. 2019;10:228. https://doi. org/10.3389/fpsyt.2019.00228.
20. Krupitsky EM. Pregabalin improves outcomes in patients with opioid withdrawal syndrome: presented at ECNP, https://www. firstwordpharma.com/node/1758126. Accessed at 1 Jan 2021.

21. Mason BJ, Crean R, Goodell V, Light JM, Quello S, Shadan F, Buffkins K, Kyle M, Adusumalli M, Begovic A, Rao S. A proof-of-concept randomized controlled study of gabapentin: effects on cannabis use, withdrawal and executive function deficits in cannabis-dependent adults. Neuropsychopharmacology. 2012;37(7):1689-98. https://doi.org/10.1038/npp.2012.14.

22. McAnally H, Bonnet U, Kaye AD. Gabapentinoid benefit and risk stratification: mechanisms over myth. Pain Ther. 2020;9(2):44152. https://doi.org/10.1007/s40122-020-00189-x ((Epub 2020 Jul 31. Erratum in: Pain Ther. 2020 Dec 4. doi: 10.1007/ s40122-020-00226-9)).

23. Lyndon A, Audrey S, Wells C, Burnell ES, Ingle S, Hill R, Hickman M, Henderson G. Risk to heroin users of polydrug use of pregabalin or gabapentin. Addiction. 2017;112(9):1580-9. https:// doi.org/10.1111/add.13843. 